\title{
Azospirillum Strains Use Phenolic Compounds as Intermediates for Electron Transfer Under Oxygen-Limiting Conditions
}

\author{
A. Barkovskii*, M.-L. Bouillant, L.J. Monrozier, J. Balandreau \\ CNRS, Laboratory of Soil Microbial Ecology, Lyon 1 University, 43 Boulevard du 11 Novembre \\ 1918, 6922 Villeurbanne Cedex, France
}

Received: 30 August 1993; Revised: 3 March 1994

\begin{abstract}
The effects of catechol, vanillic, caffeic (CAF), 2-hydroxyphenylacetic, 4-hydroxy- and 3,4-dihydroxybenzoic (3,4-DHBA) acids on the growth of a common rice rhizosphere inhabitant, Azospirillum lipoferum were studied. Two strains of this nonfermenting nitrogen-fixing bacterium were used: a motile strain (4B), and a nonmotile strain (4T). Under atmospheric conditions $\left(\mathrm{pO}_{2}=21 \mathrm{kPa}\right)$, the growth of strain $4 \mathrm{~T}$ was inhibited by catechol $(0.1 \mathrm{~mm})$ only. None of these compounds affected the growth of strain 4B. Under $5 \mathrm{kPa}$ $\mathrm{O}_{2}$, no effect was observed on strain $4 \mathrm{~B}$, whereas three of the six tested phenolics stimulated the growth of strain 4T; maximum effects were observed for 3,4-DHBA and CAF. As revealed by TLC and HPLC, under low oxygen, more new lipophilic compounds were formed from CAF by strain $4 \mathrm{~T}$, differing from CAF autooxydation products and from the products obtained under 21 $\mathrm{kPa} \mathrm{O}_{2}$. It was hypothesized that strain $4 \mathrm{~T}$ had the ability to use an oxidized derivative of CAF as a terminal electron acceptor. This hypothesis was tested in experiments under nitrogen-fixing conditions, in the absence of oxygen, and in the presence of $\mathrm{N}_{2} \mathrm{O}$ as a reoxidizing agent for CAF. Acetylene was used both as a substrate to measure nitrogenase activity (ARA) and to inhibit the biological transfer of electrons to $\mathrm{N}_{2} \mathrm{O}$. The addition of CAF in the presence of $\mathrm{N}_{2} \mathrm{O}$ had the same effect on ARA rates as an addition of oxygen. It is concluded that the strain 4T of Azospirillum lipoferum is able to sustain some of its activities (e.g., $\mathrm{N}_{2}$ fixation) using phenolics as alternative electron acceptors under low oxygen conditions.
\end{abstract}

\footnotetext{
*Present address: Civil and Environmental Engineering Department, Environmental \& Water Resources Engineering, The University of Michigan, 1351 Beal, 219 EWRE Bldg, Ann Arbor, Michigan 48109-2125.

Correspondence to: A. Barkovskii.
} 


\section{Introduction}

Phenolic compounds and their derivatives are present everywhere in the soil environment: phenolics are part of root exudates [42] and intermediates in the biodegradation of molecules containing aromatic rings (lignin, tannins from plant sources, xenobiotics from agricultural sources) [6]. They are found in water extracts of soils, roots and leaf litter [46]. They influence soil biological processes through several interactions. They are involved in chemotaxis [19, 25], allelopathic processes [21], nodulation of plants by symbiotic micoorganisms [5, 25, 33], or plant-microbe recognition processes [35]. They can be used by microorganisms as a source of carbon and energy $[4,18,26,27]$. A key feature of the microbial degradation of aromatic structures is the ortho-dihydroxylation of the aromatic ring $[1,9,26]$. The resulting polyphenolic compounds, especially 3,4-DHBA (protocatechuic acid), are widely distributed in soils [29]. These polyphenolic compounds may undergo redox reactions involving electron transfers to molecular oxygen, to other organic compounds, including various phenolics [12, 31], or to metals [10, 32]. Moreover, in soils, the polycondensation process of polyphenolic molecules is considered the basic mechanism for the genesis of humic compounds [12, 37, 30] and involves molecular oxygen consumption. Thus, by modifying electron transfers and $\mathrm{O}_{2}$ concentrations, phenolic compounds could affect microbial activities in soils.

Many activities of soil microorganisms require special $\mathrm{O}_{2}$ conditions, particularly denitrification and nitrogen fixation. It is well-known that $\mathrm{N}_{2}$ fixers have low optimal $\mathrm{pO}_{2}$ for their nitrogenase activity [7]. Heulin et al. [24], for instance, demonstrated that Azospirillum nitrogen fixation (acetylene reduction activity) was maximum at $\mathrm{O}_{2}$ concentrations close to $1 \%$, and ceased with $\mathrm{O}_{2}$ concentrations reached $8 \%$. Such optimal $\mathrm{O}_{2}$ conditions are encountered in the root environment of many crops $[13,41]$. In these rhizosphere environments, nitrogen-fixing microorganisms also find the root exudates [34] to be an abundant source of carbon. To produce the energy necessary to support their growth and nitrogenase activity [23] when $\mathrm{pO}_{2}$ is too low, alternative electron acceptors such as $\mathrm{NO}_{3}{ }^{-}$are required. The possibility that some phenolics also could play this role, cannot be rejected, due to their above-mentioned chemical properties.

Previous studies have shown some diversity in the metabolism of phenolic compounds by Azospirillum spp. It was observed that about $40 \%$ of the tested Azospirillum strains were able to metabolize benzoate or phenol in the presence of easily utilizable co-subtrates [3]. In that respect, strain 4T of Azospirillum lipoferum, isolated from the rhizosphere of rice by Thomas-Bauzon et al. [40], exhibited interesting properties: a laccase activity [17] and the ability to produce melanin-like compounds [16].

All these observations prompted us to undertake a study of the effects of simple phenolic compounds on Azospirillum lipoferum, comparing strain 4T with a more typical strain, $4 \mathrm{~B}$. A preliminary growth study under various $\mathrm{pO}_{2}$ levels confirmed that the effect of some phenolics was dependent on the redox status. The interaction between strains of Azospirillum lipoferum and phenolic compounds was then investigated more precisely, using nitrogenase activity, measured through acetylene reduction activity (ARA), to monitor the bacterial metabolism with a greater sensitivity than growth measurements. In aerobic nitrogen fixers like Azospirillum, ATP is essentially generated by the respiratory electron transport chain. If nitroge- 
nase activity is limited by the final electron acceptor concentration, ARA measurements constitute a handy and sensitive indirect measurement of the electron acceptor availability. This was used here to check the hypothesis that phenolic compounds could be used as alternative electron acceptors. In the reported experiments, the compared electron acceptors were $\mathrm{O}_{2}$ (in low concentrations to avoid ARA inhibition) and a phenolic compound (caffeic acid), alone or in combination with $\mathrm{N}_{2} \mathrm{O}$. Under these conditions, $\mathrm{N}_{2} \mathrm{O}$ could not be used as an electron acceptor, as bacterial $\mathrm{N}_{2} \mathrm{O}$ reductase was inhibited by acetylene [47]. The role of $\mathrm{N}_{2} \mathrm{O}$ was to restore the oxidized form of the phenolic compound whenever the reduced form was produced by electron transfer from bacteria.

\section{Materials and Methods}

\section{Phenolic Molecules}

Six phenolic compounds with increasing side chain lengths were chosen: catechol (CAT); 4-hydroxybenzoic acid (4HBA); 3,4-dihydroxybenzoic acid (protocatechuic acid, 3,4-DHBA); 3-methoxy-4hydroxybenzoic acid (vanillic acid, VAN); 2-hydroxyphenylacetic acid (2-HPAA), and 3,4-dihydroxycinnamic acid (caffeic acid, CAF). CAF, VAN, 4-HBA, and 3,4-DHBA are oxidative byproducts of microbial degradation of lignin-derivative compounds (ferulic and coumaric acids) [12]. CAT,3,4DHBA, and CAF rings carry two hydroxyl groups (in ortho position), whereas 4-HBA, 2-HPAA, and VAN rings carry only one hydroxyl group in ortho or para position to the acidic side chain. On the basis of results from the growth experiments (see below), caffeic acid (CAF) was selected for the electron transfer study.

\section{Bacterial Strains}

Azospirillum lipoferum 4B and 4T strains were isolated by Thomas-Bauzon et al. [40] from the rhizosphere of rice, and, more precisely, from the same individual plant. The two strains differ by morphological, genetic, and biochemical characteristics. Strain $4 \mathrm{~T}$ is a nonmotile rod, possesses a unique laccase activity [17], and aged colonies produce melanin-like compounds [16]. Strain 4B is a regular motile Azospirillum, without laccase activity. The two strains have a slightly different plasmid profile [2]. The nature and purity of strains were checked by microscopic examinations and syringaldazide tests according to Givaudan et al. [17].

Both strains were grown in $5 \mathrm{ml}$ Luria broth. Tubes were shaken overnight at $28^{\circ} \mathrm{C}$. Bacterial cells were pelleted by centrifugation $(15 \mathrm{~min}, 5000 \mathrm{~g})$, washed 3 times with sterile $0.7 \% \mathrm{NaCl}$, and then resuspended in $2 \mathrm{ml}$ of sterile $0.7 \% \mathrm{NaCl}$ solution for further assays.

\section{Growth Medium}

The effect of various electron acceptor conditions on strain growth was investigated by cultivation of the bacteria in a specific medium, supplemented or not with phenolic compounds. Solution 1: $\mathrm{NH}_{4} \mathrm{Cl}, 1$ $\mathrm{g} ; \mathrm{K}_{2} \mathrm{HPO}_{4}, 3 \mathrm{~g} ; \mathrm{KH}_{2} \mathrm{PO}_{4}, 2 \mathrm{~g}$; malic acid, $5 \mathrm{~g}$; deionized water, $948 \mathrm{ml} ; \mathrm{pH}$ (adjusted by 1 м KOH), 6.8 Solution 2: $\mathrm{MgSO}_{4} \cdot 7 \mathrm{H}_{2} 0,200 \mathrm{mg} ; \mathrm{CaCl}_{2} \cdot 2 \mathrm{H}_{2} \mathrm{O}, 26 \mathrm{mg} ; \mathrm{NaCl}, 100 \mathrm{mg} ; \mathrm{Na}_{2} \mathrm{MoO}_{4} \cdot 2 \mathrm{H}_{2} \mathrm{O}, 2$ $\mathrm{mg} ; \mathrm{MnCl}_{2} \cdot 4 \mathrm{H}_{2} \mathrm{O}, 7 \mathrm{mg}$; deionized water, $50 \mathrm{ml}$. Solution 3: $\mathrm{FeSO}_{4} \cdot 7 \mathrm{H}_{2} \mathrm{O}, 631 \mathrm{mg}$; EDTA $\cdot 2 \mathrm{H}_{2} \mathrm{O}$, $529 \mathrm{mg}$; deionized water, $50 \mathrm{ml}$. All solutions were autocalved separately at $120^{\circ} \mathrm{C}$ for $20 \mathrm{~min}$. Solution 1 and solution 2 were mixed and then supplemented with $1 \mathrm{ml}$ of solution 3 . One milliliter of a filter-sterilized solution of biotin $\left(0.1 \mathrm{~g} \mathrm{liter}^{-1}\right)$ was added in the mixture to obtain a final concentration 
of $10^{-5} \mathrm{~g} \mathrm{liter}^{-1}$. Filter-sterilized phenolic compound solutions $(10 \mathrm{mM})$ were added when required in growth flasks to a $0.1 \mathrm{~mm}$ final concentration.

\section{Growth Conditions}

For growth experiments, $0.05 \mathrm{ml}$ of cell suspension in $0.7 \% \mathrm{NaCl}$ was introduced in 150 -ml incubation flasks containing $30 \mathrm{ml}$ of the above growth medium. Two oxygen levels in flask head spaces were used: atmospheric conditions, i.e., around $21 \% \mathrm{O}_{2}\left(\mathrm{O}_{2}\right.$ partial pressure $\left.=21 \mathrm{kPa}\right)$ and $5 \% \mathrm{O}_{2}\left(\mathrm{O}_{2}\right.$ partial pressure $=5 \mathrm{kPa}$ ). Flasks with atmospheric $\mathrm{O}_{2}$ were capped with cotton plugs whereas flasks with low $\mathrm{pO}_{2}$ with capped with gas-tight rubber stoppers. In the low $\mathrm{pO}_{2}$ treatments, flasks were evacuated 3 times, filled with Helium (high grade) of which $5 \%$ was then replaced by pure $\mathrm{O}_{2}$ before injecting the inoculum and the phenolic compound. Cultivation under atmospheric conditions was performed for $48 \mathrm{~h}$ in the dark at $28^{\circ} \mathrm{C}$ on a horizontal rotary shaker $(60 \mathrm{rpm})$. One-milliliter medium samples were taken after $0,18,24,39,44$, and $48 \mathrm{~h}$ of incubation. Cultivation under low $\mathrm{O}_{2}$ conditions was performed in sealed flasks for $88 \mathrm{~h}$ under the same conditions. One milliliter medium samples were taken after $0,22,44,48,64,69$, and $88 \mathrm{~h}$ of incubation. Each incubation was performed in triplicate. Control incubations were conducted without phenolic compounds added. Bacterial growth was measured by optical density of cell suspensions at $540 \mathrm{~nm}$.

\section{Acetylene Reduction Activity (ARA)}

Flasks $(150 \mathrm{ml})$ were filled with $30 \mathrm{ml}$ of $\mathrm{N}$-free medium (growth medium described above, without $\mathrm{NH}_{4} \mathrm{Cl}$ ), evacuated 3 times, and then filled using Helium plus $10 \% \mathrm{C}_{2} \mathrm{H}_{2}$. The residual $\mathrm{O}_{2}$ partial pressure, measured by gas chromatography (catharometer detector), was less than $0.1 \mathrm{kPa}$. Onemilliliter aliquot volumes of cell suspension in $0.7 \% \mathrm{NaCl}$ sterile solution were introduced into the flasks. Flasks were incubated at $28^{\circ} \mathrm{C}$ in the dark, without agitation for $120 \mathrm{~h}$. At this time various treatments were applied: control, $0.3 \mathrm{ml}$ of $0.7 \% \mathrm{NaCl}$ sterile solution; $\mathrm{CAF}, 0.3 \mathrm{ml}$ of $10 \mathrm{~mm}$ solution of CAF; $\mathrm{O}_{2}, \mathrm{O}_{2}$ introduced into the flask headspace to a partial pressure of $0.5 \mathrm{kPA} ; \mathrm{N}_{2} \mathrm{O}, \mathrm{N}_{2} \mathrm{O}$ introduced into the flask headspace to a partial pressure of $1.3 \mathrm{kPa}$; $\mathrm{CAF}+\mathrm{N}_{2} \mathrm{O}, 0.3 \mathrm{ml}$ of $10 \mathrm{mM}$ solution of $\mathrm{CAF}$ and $\mathrm{N}_{2} \mathrm{O}$ introduced into the flask headspace to a partial pressure of $1.3 \mathrm{kPa}$. Treatments were carried out in triplicate. Flasks were further incubated without shaking for $204 \mathrm{~h}$ (total incubation time was $324 \mathrm{~h}$ ). ARA was assayed after $0,18,22,36,66,88,100,120,144,188,200$, $220,280,310$, and $324 \mathrm{~h}$ of incubation. Ethylene in flasks was measured by gas chromatography (FID detector).

\section{Redox Potential}

The redox potential (Eh) was measured by a platinum electrode (Ingold Pt 4850 DXUS8, AG Industrie, Steinbach, Germany) connected to a $\mathrm{mV}$ meter (CG 837, SOLEA, Lyon, France). The electrode was placed in the culture medium immediately after opening the flask. Redox potential values changed from high values on electrode insertion, to lower values when equilibrated, and then to higher values again when atmospheric $\mathrm{O}_{2}$ diffused into the liquid medium. The values of the lower point of the curve were considered as reflecting the redox potential of the medium.

\section{Caffeic Acid Metabolites Extraction and Characterization}

Thin layer (TLC) and high performance liquid (HPLC) chromatography were used to characterize caffeic acid and its metabolites. Metabolites of CAF were extracted from the medium after an 88-h incubation by ethylacetate ( $\mathrm{vol} / \mathrm{vol}, 3$ times). The extracts were concentrated under vacuum in a rotary 


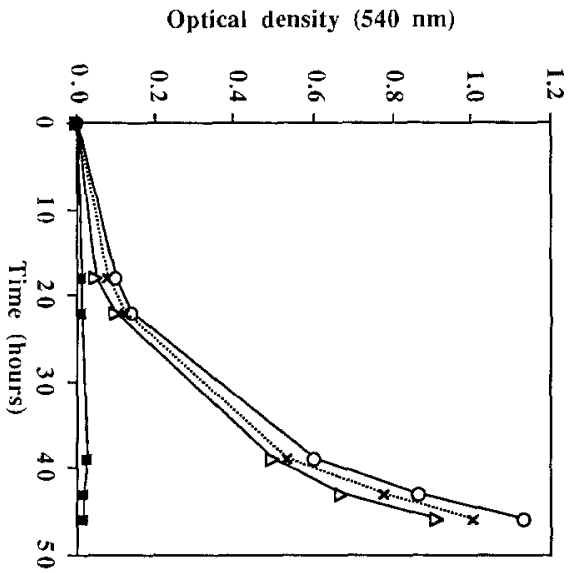

Fig. 1. Influence of the selected phenolic compounds on growth of strain 4T of Azospirillum lipoferum under atmospheric conditions. The standard errors of the means were $<5 \%$ in all cases. Symbols: (-O-), control; (- -), 3.4-DHBA; (- - ), catechol; $(\cdots \times \cdots)$, CAF. 4-HBA, 2-HPAA, and VAN (not represented) gave results undistinguishable from CAF, 3,4-DHBA, and control.

evaporator and dissolved in $0.1 \mathrm{ml}$ of high-grade methanol. TLC was performed on aluminum sheets coated with silica gel F254 (Merck, Darmstadt, Germany). CAF and its metabolites were separated by migration in toluene: acetic acid (5:1) mixture. TLC chromatograms were observed at 254 and $360 \mathrm{~nm}$, and compounds were revealed by the Merck diazotized benzidin reagent for phenols. HPLC was performed on a 625L System, equipped with a Microbondapak C18 column (Waters, Milford, Mass.). A first analysis was performed using a gradient of $\mathrm{H}_{2} \mathrm{O}+2 \%$ acetic acid (A) and acetonitrile (B) (WAA gradient). The WAA gradient conditions were as follows: $0-40 \mathrm{~min}, \mathrm{~A}=100 \%$; $40-45 \mathrm{~min}$, $\mathrm{A} / \mathrm{B}=60 / 40 ; 45-50 \mathrm{~min}, \mathrm{~A}=100 \%$; the flow rate was $1.5 \mathrm{ml} \mathrm{min}^{-1}$. A second analysis was done under isocratic conditions with pure acetonitrile (flow rate $1.5 \mathrm{ml} \mathrm{min}{ }^{-1}$ ). Eluted compounds were detected using a 991 Photodiode Array Detector (Waters).

\section{Results}

\section{Growth}

The influence of the chosen phenolic compounds on the growth of strains $4 \mathrm{~B}$ and 4T of A. lipoferum was investigated first. Under atmospheric conditions, growth of strain $4 \mathrm{~B}$ was not affected by any of the studied compounds (data not shown). The growth of strain $4 \mathrm{~T}$ was strongly inhibited by CAT, whereas the other compounds (3,4-DHBA, 4-HBA, CAF, VAN, and 2-HPAA) had no influence (Fig. 1). Under $5 \mathrm{kPa} \mathrm{O}$, the growth of strain $4 \mathrm{~T}$ was stimulated by three of the six tested compounds, namely 3,4-DHBA $\geqslant \mathrm{CAF}>2$-HPAA (Fig. 2). VAN, CAT, and 4-HBA either slightly stimulated or did not influence growth of strain 4T. Under this low $\mathrm{O}_{2}$ partial pressure, growth of strain $4 \mathrm{~B}$ was not influenced by any of these phenolic compounds (data not shown). 


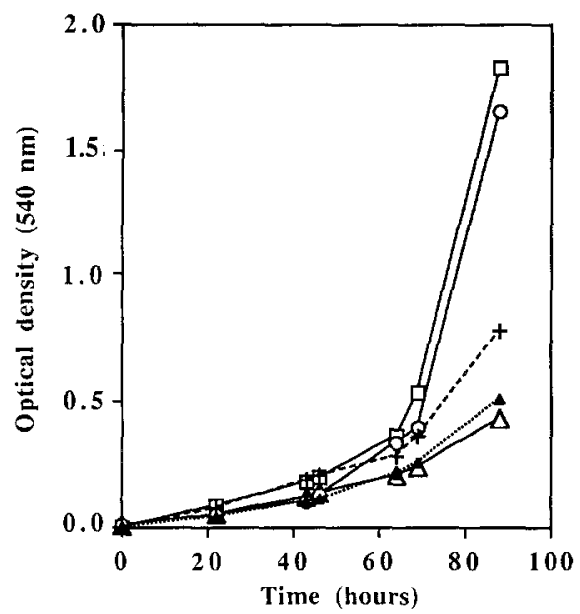

Fig. 2. The growth stimulation of strain 4T of Azospirillum lipoferum by phenolics under $5 \mathrm{kPa} \mathrm{O}_{2}$. The standard errors of the means were $<5 \%$ in all cases. Symbols: $(--)$, control; $(-\square-)$, 3,4-DHBA; (-O-), CAF; (--+--), 2-HPAA; $(\cdots \wedge)$, catechol. 4-HBA and VAN (not represented) gave results undistinguishable from CAT and the control.

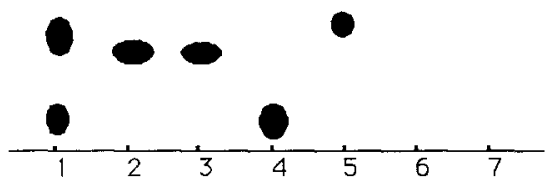

Fig. 3. TLC chromatogram of the products of caffeic acid incubation with Azospirillum strains under $21 \mathrm{kPa} \mathrm{O}_{2}$ and $5 \mathrm{kPa} \mathrm{O}$ conditions. Run number: 1, caffeic acid fresh standard solution; 2, caffeic acid + strain $4 \mathrm{~B}$ under $21 \mathrm{kPa} \mathrm{O}_{2} ; 3$, caffeic acid + strain $4 \mathrm{~T}$ under $21 \mathrm{kPa} \mathrm{O}_{2} ; 4$, caffeic acid + strain $4 \mathrm{~B}$ under $5 \mathrm{kPa} \mathrm{O}_{2} ; 5$, caffeic acid + strain $4 \mathrm{~T}$ under $5 \mathrm{kPa} \mathrm{O}_{2} ; 6$, caffeic acid, sterile incubation under $5 \mathrm{kPaO}_{2} ; 7$, caffeic acid, sterile incubation under $21 \mathrm{kPa} \mathrm{O}_{2}$. This figure depicts the compilation of the spot locations as revealed by UV light $(254$ and $360 \mathrm{~nm}$ ) and the Merck diazotized benzidin reagent for phenols.

\section{Thin Layer Chromatography}

TLC chromatograms are summarized in Fig. 3. The ethylacetate/methanol extract of non-incubated, sterile, fresh caffeic acid solution was eluted as two spots exhibiting bright blue fluorescence. Extracts from caffeic acid incubated $(88 \mathrm{~h})$ under sterile conditions in both atmospheric and $5 \mathrm{kPa}$ partial pressure $\mathrm{O}_{2}$ conditions were eluted as two spots with higher $\mathbf{R}_{f}$, values showing a much more lipophilic characteristic than components from the fresh caffeic acid solution. 
Table 1. HPLC analysis of major products resulting from the incubation of strains $4 \mathrm{~T}$ and $4 \mathrm{~B}$ of Azospirillum lipoferum with caffeic acid. For HPLC conditions see Text (Materials and Methods)

\begin{tabular}{|c|c|c|c|c|c|c|}
\hline \multirow[b]{2}{*}{ Treatment } & \multicolumn{3}{|c|}{ WAA gradient } & \multicolumn{3}{|c|}{ Pure acetonitrile } \\
\hline & $\begin{array}{c}\text { Peak } \\
\text { number }\end{array}$ & $\lambda \max ($ O.D.) & $\begin{array}{l}\text { Retention } \\
\text { time (min) }\end{array}$ & $\begin{array}{c}\text { Peak } \\
\text { number }\end{array}$ & $\lambda \max$ (O.D.) & $\begin{array}{l}\text { Retention } \\
\text { time (min) }\end{array}$ \\
\hline \multirow{4}{*}{$\begin{array}{r}\mathrm{CAF} \text { (fresh } \\
\text { solution) }\end{array}$} & 1 & $237(0.18)$ & 16.75 & none & & \\
\hline & $E_{\max }$ & $323(0.30)$ & & & & \\
\hline & 2 & $237(0.21)$ & 17.80 & none & & \\
\hline & & $323(0.35)$ & & & & \\
\hline CAF & none & & & 1 & $272(0.18)$ & 1.4 \\
\hline \multicolumn{7}{|l|}{$\left(\right.$ atm. condit.) ${ }^{a}$} \\
\hline $4 \mathrm{~B}+\mathrm{CAF}$ & 1 & $234(0.41)$ & 18.16 & none & & \\
\hline (atm. condit.) & & $323(0.64)$ & & & & \\
\hline $4 \mathrm{~T}+\mathrm{CAF}$ & 1 & $237(0.11)$ & 17.96 & none & & \\
\hline (atm. condit.) & & $323(0.18)$ & & & & \\
\hline & \multicolumn{5}{|c|}{$\left(5 \mathrm{kPa} \mathrm{O} \mathrm{O}_{2}\right)$} & 3.4 \\
\hline \multirow{4}{*}{$\begin{array}{l}4 \mathrm{~B}+\mathrm{CAF} \\
\left(5 \mathrm{kPaO} \mathrm{O}_{2}\right)\end{array}$} & 1 & $225(0.14)$ & 17.35 & none & & \\
\hline & & $345(0.11)$ & & & & \\
\hline & 2 & 234 (traces) & 17.96 & none & & \\
\hline & & 327 (traces) & & & & \\
\hline \multirow{4}{*}{$\begin{array}{l}4 \mathrm{~T}+\mathrm{CAF} \\
\left(5 \mathrm{kPa} \mathrm{O}_{2}\right)\end{array}$} & 1 & $236(0.11)$ & 17.92 & 1 & $247(0.6)$ & 2.12 \\
\hline & & $323(0.18)$ & & & $334(0.35)$ & \\
\hline & 2 & $230(0.18)$ & 22.82 & 2 & $281(0.1)$ & 2.4 \\
\hline & & & & 3 & $280(0.1)$ & 3.4 \\
\hline
\end{tabular}

${ }^{\mathrm{a}} \mathrm{Atm}$. condit, atmospheric conditions of $21 \mathrm{kPa} \mathrm{O}_{2}$.

Incubation under atmospheric $\mathrm{O}_{2}$ with both strains resulted in a one-spot chromatogram. This spot exhibited similar $\mathrm{R}_{f}$ but weaker blue/yellow fluorescence when compared to the higher $\mathrm{R}_{f}$ spot of fresh caffeic acid. Under low $5 \mathrm{kPa} \mathrm{O}$ conditions, contrasting results were obtained with strains $4 \mathrm{~B}$ and $4 \mathrm{~T}$. Under these limiting $\mathrm{O}_{2}$ conditions, caffeic acid incubated with $4 \mathrm{~B}$ strain resulted in one spot with the lowest $\mathrm{R}_{f}$ of all the TLC runs. With $4 \mathrm{~T}$ strain, three spots were obtained: the less lipophilic compound (lower $\mathrm{R}_{f}$ ) had a bright blue fluorescence and was close to the more lipophilic component of fresh caffeic acid, but it did not persist after $24 \mathrm{~h}$ in the methanol extract or on the chromatogram run; the compound with the more lipophilic $\mathrm{R}_{f}$ was close to the more lipophilic component from sterile caffeic acid incubation under limited $5 \mathrm{kPa} \mathrm{O}$; and a new spot appeared in the intermediate zone of $\mathrm{R}_{f}$.

\section{High Performance Liquid Chromatography}

HPLC confirmed and refined most of the TLC results. Results are summarized in Table 1. (1) HPLC analysis of fresh caffeic acid resulted in two peaks (two spots in TLC) eluted at 16.75 and $17.80 \mathrm{~min}$, respectively. Both compounds had identical UV spectra with two absorption maxima at 237 and $323 \mathrm{~nm}$ and correspond to the two stereoisomers of caffeic acid; the two isomers were present in nearly equal 
concentrations. No peak was detected with pure acetonitrile. (2) Products of caffeic acid incubation under sterile conditions either under 21 or $5 \mathrm{kPa} \mathrm{O}_{2}$ were eluted by pure acetonitrile only as one peak after $1.4 \mathrm{~min}$ and $3.4 \mathrm{~min}$, respectively, and traces of less lipophilic components were eluted in the WAA gradient. (3) Incubation of caffeic acid with strain $4 \mathrm{~B}$ under $21 \mathrm{kPa} \mathrm{O}_{2}$ resulted in one peak eluted by the WAA gradient at $18.16 \mathrm{~min}$ (i.e., $36 \mathrm{sec}$ later than the second peak of CAF fresh solution) with O.D. maxima at 234 and $323 \mathrm{~nm}$. This absorption spectrum is very similar to the spectra of the two isomers found in the fresh solution of caffeic acid. The same incubation conditions with strain $4 \mathrm{~T}$ also resulted in one peak, with the same retention time $(17.96 \mathrm{~min})$ but with O.D. at 237 and $323 \mathrm{~nm}$, consistently lower (1/4) than with strain $4 \mathrm{~B}$.

Under low $\mathrm{O}_{2}$ conditions, strains $4 \mathrm{~B}$ and $4 \mathrm{~T}$ gave completely different HPLC patterns of caffeic acid biotransformation. (1) Strain 4B products were represented by only traces of 234 to $327-\mathrm{nm}$ absorbing substance at $17.96 \mathrm{~min}$, and by a main peak at 225 and $345 \mathrm{~nm}$ which eluted at $17.35 \mathrm{~min}$, i.e., a weakly lipophilic product (as in TLC run). (2) Strain 4T products were partly eluted in the WAA gradient with two main peaks, one at $17.92 \mathrm{~min}$ with O.D. maxima at 236 and $323 \mathrm{~nm}$ (i.e., very close to the more lipophilic product from fresh caffeic acid solution), and one at 22.82 min with one maximum absorbance peak at $230 \mathrm{~nm}$. This last peak corresponded to a new component unrelated to any other caffeic acid products (as was the intermediate $\mathrm{R}_{f}$ spot in the TLC assay). Three other products were eluted in pure acetonitrile. The main component, a new product, was recovered after $2.12 \mathrm{~min}$ and strongly absorbed at 247 and $334 \mathrm{~nm}$. The third component and the product of sterile caffeic acid incubated in $5 \mathrm{kPa} \mathrm{O}$ exhibited similar HPLC properties.

\section{Nitrogenase Activity}

Nitrogenase activity was assayed by ARA. Only strain 4T of A. lipoferum was considered because of its specific reaction when polyphenolics were added in the growth medium and because ARA of strain 4B was not influenced by the addition of caffeic acid in any combinations (data not shown). As described in Materials and Methods, ARA of 4T strain was first assayed for $120 \mathrm{~h}$ in the N-free growth medium. After a lag phase (Fig. 4), ARA increased up to $27 \mathrm{nmol}$ of $\mathrm{C}_{2} \mathrm{H}_{4}$ produced per hour in all flasks, continued until day 3 and then stopped completely. Up to day $3(66 \mathrm{~h})$, ARA averaged to $20 \mathrm{nmol}$ of $\mathrm{C}_{2} \mathrm{H}_{4}$ produced per hour and per flask.

At $120 \mathrm{~h}$, the injection of an electron acceptor in the treated samples or of $0.7 \%$ $\mathrm{NaCl}$ solution in the control flasks, produced a temporary slight increase in ARA (approximately 2-4 nmol h${ }^{-1}$ flask $^{-1}$ ). Forty-four hours after this injection (i.e., $164 \mathrm{~h}$ after the experiment began), ARA started again in $\mathrm{O}_{2}$ and $\mathrm{N}_{2} \mathrm{O}+\mathrm{CAF}$ treatments and continued during the following $86 \mathrm{~h}$ until day 10 , and then stopped again. At $300 \mathrm{~h}$, ARA had ceased in all treatments. ARA levels of $\mathrm{O}_{2}$ and $\mathrm{N}_{2} \mathrm{O}+\mathrm{CAF}$ treatments were similar and higher than in the control, $\mathrm{N}_{2} \mathrm{O}$, or CAF treatments (Fig. 4). $\mathrm{N}_{2} \mathrm{O}$ and $\mathrm{CAF}$ treatments exhibited the same ARA as the control. 


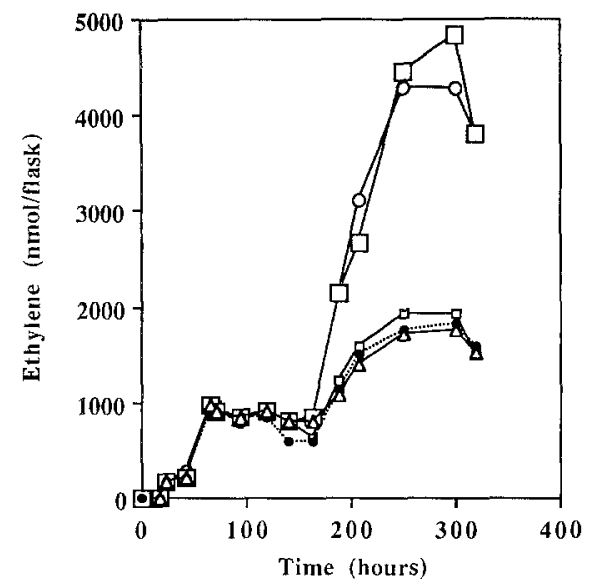

Fig. 4. Acetylene reducing activity of strain 4T of Azospirillum lipoferum under electron acceptorlimiting conditions. Caffeic acid and gases were added at hour 120 . The standard errors of the means were $<4 \%$ in all cases. Symbols: ( $-\square-)$, control; $(-\mathrm{O}-)$, treament by $\mathrm{O}_{2} ;(-\square-)$, treatment by $\mathrm{CAF}+\mathrm{N}_{2} \mathrm{O} ;(--)$, treatment by CAF; $(-\triangle-)$, treatment by $\mathrm{N}_{2} \mathrm{O}$.

\section{Redox Potential}

During the first $120 \mathrm{~h}$ of the ARA experiment, the redox potential decreased from $255 \mathrm{mV}$ to $94 \mathrm{mV}$ (Fig. 5). The introduction of $\mathrm{O}_{2}$ increased the redox potential of the medium to $120 \mathrm{mV}$. Redox potential of the samples receiving other electron acceptors was unchanged. In later measurements, the redox potential of control samples was still decreasing progressively. At the same time, the redox potential of $\mathrm{N}_{2} \mathrm{O}+\mathrm{CAF}$ remained unchanged up to $250 \mathrm{~h}$ and then slowly decreased. The difference between $\mathrm{N}_{2} \mathrm{O}+\mathrm{CAF}$ and control treatments at the end of the experiment was around $20 \mathrm{mV}$. Redox potential of the medium supplemented by CAF only was slightly higher than the control for $44 \mathrm{~h}$ and then rapidly decreased to a lower level than the control. In the $\mathrm{O}_{2}$ treatment, maximum redox potential was reached by 250 $\mathrm{h}$ of incubation $(140 \mathrm{mV})$, and then decreased.

\section{Discussion}

The role of phenolic compounds in growth and nitrogenase activity was investigated in two Azospirillum lipoferum strains. A. lipoferum 4B and 4T were selected for their contrasting properties under high and low oxygen partial pressure and their different interactions with phenolics $[16,17,24]$.

The investigated phenolics were chosen as representatives of the various molecular structures of mono- and diphenolic compounds that are likely to be encountered in the rhizosphere environment. Except catechol, each tested compound had a carbon side chain with a carboxylic functional group. With the exception of 2-hydroxyphenylacetic acid, 4-hydroxybenzoic acid, and 3-methoxy-4-hydroxybenzoic acid, studied molecules were diphenols, which are able to form quinoid structures and accept electrons from a convenient electron donor. All the tested molecules 


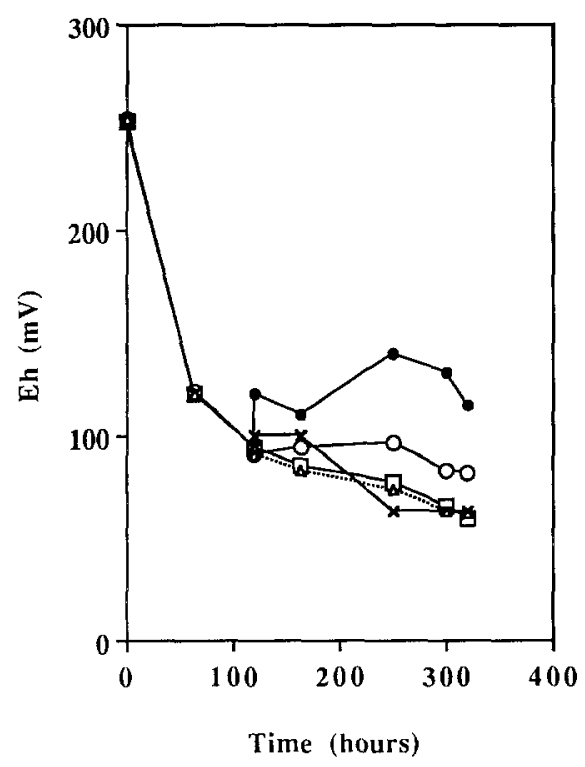

Fig. 5. Redox potential values in the culture medium when strain $4 \mathrm{~T}$ of Azospirillum lipoferum was grown under electron acceptor-limiting conditions. Caffeic acid and gases were added at hour 120 , Symbols: $(-\square)$, control; $(\bullet)$, treatment by $\mathrm{O}_{2} ;(-\circ)$, treatment by CAF $+\mathrm{N}_{2} \mathrm{O} ;(\multimap *)$, treatment by CAF; $(\cdots \Delta \cdots)$, treatment by $\mathrm{N}_{2} \mathrm{O}$.

could also exist in a free radical form with unpaired electrons, a form able to accept electrons as well.

\section{Strain $4 B$}

As far as we know, high oxygen concentrations can depress nitrogenase, but do not limit the growth of $A$. lipoferum strains if the supply of nitrogen is not limiting. In the first experiment, with an ample supply of nitrogen, control treatments under atmospheric oxygen conditions exhibited the highest growth rates. Under these conditions, strain 4B growth was unaffected by the addition of any of the phenolics at $0.1 \mathrm{~mm}$ concentrations. The carbon supplied as a phenolic compound was approximately $1 \%$ of the carbon provided by malate in the growth medium, so that phenolics could not be expected to have an effect as an extra carbon source. The absence of detectable effects on strain 4B growth means that they are not toxic, whatever the oxygen supply. Nevertheless, TLC and HPLC data showed that caffeic acid was modified by strain 4B. In a fresh solution to CAF, two signals (spots or peaks) were observed, corresponding to its two isomers. In the presence of strain $4 \mathrm{~B}$, the incubation of $\mathrm{CAF}$ under $21 \mathrm{kPa} \mathrm{O}_{2}$ resulted in only one compound. The UV spectrum of this compound was very similar to both CAF isomer spectra observed in the fresh solution, with two absorption maxima nearly at the same wavelengths, and a longer retention time. The UV absorption of each of the two peaks of this compound was the sum of the absorption of the corresponding peaks in the UV spectrum of fresh caffeic acid isomers. This strongly suggests that under 


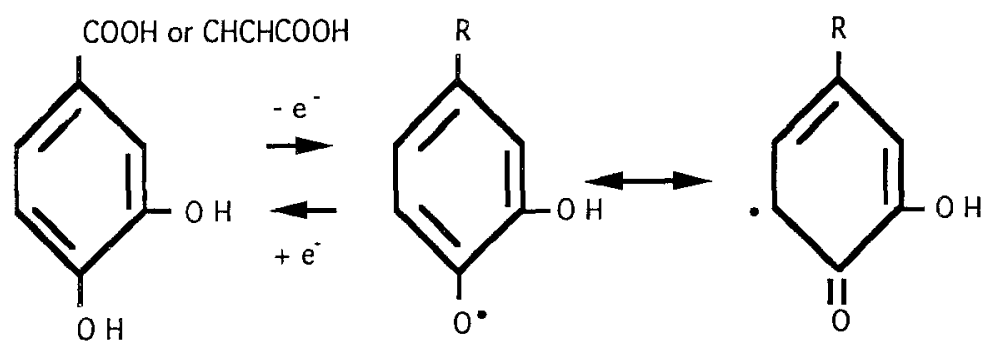

Fig. 6. Possible redox forms and equilibria for caffeic or 3,4-DHBA acid derivatives.

atmospheric conditions, strain 4B did not catabolize CAF but produced a dimer from the two isomers. This unexpected "protection" of the caffeic acid structure against non-biological transformation during the $21 \mathrm{kPa} \mathrm{O}_{2}$ incubation with strain $4 \mathrm{~B}$ may be due to the metabolic consumption of reactive components of the medium (dissolved $\mathrm{O}_{2}$, FeIII) by strain $4 \mathrm{~B}$. In this case, it is likely that the bacteria and the molecule had few, if any, interactions. Under low $\mathrm{O}_{2}$ conditions, only traces of this possible dimer were found together with low amounts of a new phenolic metabolite showing a strong alteration of the CAF molecule.

\section{Strain $4 T$}

Under atmospheric conditions, the addition of a small quantity of phenolic compounds contrastingly affected $4 \mathrm{~T}$ strain growth. Caffeic acid and 3,4-dihydroxybenzoic acid slightly depressed $4 \mathrm{~T}$ strain development when catechol dramatically reduced the growth. Catechol reactivity with amino compounds is known [12], as well as the subsequent inhibition of enzymatic activities by orthoquinones [36], but why 4T strain growth was specifically inhibited by catechol remains unclear. Carboxy substituted rings were less active, which could mean that they did not exist directly as quinone but more likely as less oxidized forms, like semiquinone, or with only one unpaired electron as a free radical.

The results of the cultivation of the $4 \mathrm{~T}$ strain under $5 \mathrm{kPa} \mathrm{O}_{2}$ showed a strong improvement in growth on 3,4-DHBA and CAF. The contrasting effect of 3,4DHBA and CAF on strain $4 \mathrm{~T}$ growth under $5 \mathrm{kPA} \mathrm{O}_{2}$ (stimulation) and $21 \mathrm{kPa} \mathrm{O}_{2}$ (very slight depletion) raised the hypothesis that these phenolic compounds could offer an alternative acceptor for electron transfer from bacterial respiration. The electron transfer requires that the phenolic compounds exist, at least partly, under oxidized forms, as shown in Fig. 6. These partially oxidized forms of phenolic acids could be further reduced by electron donors from a chemical process like the FeII/FeIII redox reaction $[10,32]$, or possibly from bacterial metabolism. The fact that 3,4-DHBA and CAF similarly affected $4 \mathrm{~T}$ strain growth suggested that the ethylenic group of the side chain of caffeic acid was not involved in the electron transfer process.

The nonmotile 4T strain not only was more sensitive to the presence of the phenolic compounds but also more severely affected the caffeic acid structure in both atmospheric and limited $\mathrm{O}_{2}$ conditions. Under atmospheric conditions, strain 
4T utilized caffeic acid as an additional source of carbon and energy, since HPLC revealed only one-fourth of the initial absorbance of caffeic acid without appearance of other compounds. It is noteworthy that strain 4T under atmospheric conditions and strain $4 \mathrm{~B}$ under $5 \mathrm{kPa} \mathrm{O}$ exerted a similar influence on caffeic acid transformations. Under $5 \mathrm{kPA} \mathrm{O}$, the presence of caffeic acid stimulated the growth of the 4T strain whereas four new (compared to the atmospheric incubation) byproducts (Table 1) appeared, one of them exhibiting strong HPLC similarities to one compound produced during the sterile incubation of CAF.

The pattern of byproducts obtained by TLC and HPLC evidenced the complexity of the metabolism of caffeic acid. Under sterile conditions CAF has been transformed by chemical processes. It is well-known that polyphenolics (including CAF) are not stable in aqueous solutions, in contrast to the monophenolic compounds. Transformation by autooxidation [14], photodegradation [39], and interaction with metallic ions $[10,31,32]$ have been described. Our TLC and HPLC data showed that similar byproducts of CAF autodegradation (mostly highly lipophilic compounds that were not eluted by the aqueous solutions) were obtained either in atmospheric or in limiting- $\mathrm{O}_{2}$ conditions $(5 \mathrm{kPa})$. Except for one of the acetonitrile spots of the 4T strain incubation under $5 \mathrm{kPa}$ of $\mathrm{O}_{2}$, the byproducts of the bacterial metabolism of CAF were different (less lipophilic) from the compounds produced under sterile conditions.

From this first experiment, it could be inferred that the stimulation of 4T strain growth by caffeic acid did not result from the carbon supply but from another process. Under atmospheric conditions this process contributed to the aromatic ring fission and to the assimilation of the resulting aliphatic molecules by the bacteria (a metabolic pathway that was used by the $4 \mathrm{~B}$ strain under low $\mathrm{O}_{2}$ conditions only). Under limiting $\mathrm{O}_{2}$ conditions, this process provided an improvement of electron acceptor accessibility, allowing the bacteria to restore metabolism at the same level as under atmospheric conditions. The question arose whether phenolics would facilitate the access of electrons to remaining traces of oxygen or would constitute an actual alternative electron acceptor after oxygen exhaustion. However, the limitation of $\mathrm{O}_{2}$ as a metabolic electron acceptor was not easy to demonstrate at 5 $\mathrm{kPa} \mathrm{O}_{2}$ when measuring growth only. It was thus decided to use nitrogenase activity, as Azospirillum is a nitrogen-fixing organism. Nitrogenase activity measurement through acetylene reduction (ARA) is a much more sensitive measurement of microbial activity, and it is highly dependent on ATP generated through the respiratory electron transport chain.

In the second experiment, remaining $\mathrm{O}_{2}$ was rapidly exhausted as an electron acceptor, and the experiment was designed to restore the ATP-generating ability of the respiratory chain with new electron acceptors; oxygen and $\mathrm{N}_{2} \mathrm{O}$. The latter cannot be used directly as the metabolic electron acceptor in the presence of acetylene [45], and its reduction would reveal the role of the phenolic compound as alternative metabolic terminal acceptor. $\mathrm{N}_{2} \mathrm{O}$ would generate the oxidized form of the phenolic compound, allowing it to accept new electrons and thus restart ATP generation. This new production of ATP would be immediately revealed by ARA, as under acetylene the use of ATP for growth is very limited [20].

During the first $120 \mathrm{~h}$, strain $4 \mathrm{~T}$ inoculum consumed most of the electron acceptors present in the medium. The average ARA rate during the active period was slightly lower than expected from the results of a previous study by Heulin et 
al. [24]. Twenty nanomoles of $\mathrm{C}_{2} \mathrm{H}_{2}$ reduced per hour and per $10^{8}$ cells was obtained with a long-term incubation, whereas in short-term incubation $(3 \mathrm{~h}$ ) ARA was undetectable, both under $10 \mathrm{kPA} \mathrm{C}_{2} \mathrm{H}_{2}$ and $0.5 \mathrm{kPa} \mathrm{O} \mathrm{O}_{2}$ [22]. The electron acceptor-limiting conditions were attained when available oxygen had been consumed in the closed vials, i.e., between 36 and $66 \mathrm{~h}$ (Fig. 4). At that stage, the addition of oxygen triggered a new phase of ARA, confirming that the amount of electron acceptor was the limiting factor and that enough malate had been supplied as a source of carbon and energy. The introduction of the $\mathrm{NaCl}$ solution in the control at $120 \mathrm{~h}$ caused a stimulation of ARA after $44 \mathrm{~h}$ of further incubation, indicating that some $\mathrm{O}_{2}$ was introduced during the addition of the reagent solution. The resulting $\mathrm{C}_{2} \mathrm{H}_{4}$ production $\left(1950-911=1039 \mathrm{nmol}^{\text {flask }}{ }^{-1}\right)$ corresponded to approximately $2.1 \times 10^{-6} \mathrm{~mol}$ of $\mathrm{e}^{-}$transferred to $\mathrm{C}_{2} \mathrm{H}_{2}$. The addition of $\mathrm{N}_{2} \mathrm{O}$ at $1.3 \mathrm{kPa}$ or of $\mathrm{CAF}$ at $0.1 \mathrm{~mm}$ concentration resulted in the same low ARA and redox potential changes as in the control treatment. The introduction of $\mathrm{O}_{2}$ at 0.5 $\mathrm{kPa}$ or of $\mathrm{N}_{2} \mathrm{O}$ at $1.3 \mathrm{kPa}$ in the flask provided a potential for electron acceptance of approximately $107 \times 10^{-6} \mathrm{~mol}$ of $\mathrm{e}^{-}$and $139 \times 10^{-6} \mathrm{~mol}$ of $\mathrm{e}^{-}$, respectively. As mentioned above, $\mathrm{N}_{2} \mathrm{O}$ was not able to directly play the role of electron acceptor for the $4 \mathrm{~T}$ strain. In contrast, $0.5 \mathrm{kPa} \mathrm{O}$ could act as a terminal electron acceptor for strain 4T which exhibited ARA after some hours when $\mathrm{O}_{2}$ had diffused into the medium and redox potential increased.

For electron transfer, the added CAF at $0.1 \mathrm{~mm}$ could accept approximately $3 \times 10^{-6} \mathrm{~mol}$ of $\mathrm{e}^{-1}$ in the semi-quinone or free radical form, and $6 \times 10^{-6} \mathrm{~mol}$ of $\mathrm{e}^{-}$in the quinone form. CAF introduced in a 95-mV medium should exist in a reduced form only, and, as expected, this treatment did not stimulate ARA. Probably, the low increase of redox potential of the medium immediately after the addition of caffeic acid was due to the existence of a partly oxidized form in the solution at the moment of introduction. The redox potential of the medium supplied with $\mathrm{N}_{2} \mathrm{O}+\mathrm{CAF}$ remained constant during the later part of the incubation, and the difference in redox values between this treatment and the control was around 20 $\mathrm{mV}$ at the end of the experiment. Therefore, the presence of CAF resulted in a 20 $\mathrm{mV}$ increase in redox potential (relative to other conditions). This is consistent with the results obtained by Einarsdottir et al. [11] and would suggest the presence of the oxidized form of the phenolic molecule due to the action of $\mathrm{N}_{2} \mathrm{O}$, an oxidizing agent, i.e, a chemical electron acceptor. The cointroduction of CAF and an oxidizing agent resulted in maximal ARA stimulation. In $\mathrm{N}_{2} \mathrm{O}+\mathrm{CAF}$ treatments, the increase of ARA compared to control was $2893 \mathrm{nmol}$ of $\mathrm{C}_{2} \mathrm{H}_{4}$ produced. The production of this amount of $\mathrm{C}_{2} \mathrm{H}_{4}$ required $5.8 \times 10^{-6} \mathrm{~mol}\left(2.9 \times 10^{-6} \times 2\right) \mathrm{mol}$ of $\mathrm{e}^{-}$, which is approximately the $\mathrm{e}^{-}$transfer capacity of caffeic acid if the quinonic form predominates $\left(6 \times 10^{-6} \mathrm{~mol}\right.$ of $\left.\mathrm{e}^{-}\right)$.

\section{Conclusion}

The capacity of phenolic compounds to act chemically as electron donors or acceptors has been recognized for a long time [43, 44], as well as the capacity of electron-transfer properties of phenolics to interfere with the functioning of enzymes $[8,11,15]$. The ability of phenolics to stimulate the respiration of soil microorganisms $[38,45]$, as well as the enhancement of their nitrogenase activity 
[28], has also been reported. However, as far as we know, it has never been suggested that this stimulation proceeds through an enzymatic electron transfer system allowing microaerophilic bacteria, in the absence of oxygen, to use phenolic compounds as intermediates towards a chemical electron acceptor. The above report of the capacity of caffeic acid to be used as an electron transfer molecule by a nonmotile Azospirillum lipoferum strain is coincidental with the discovery that such strains also have the capacity to bring about oxidative transformations of phenolic compounds [17]. This suggests that the adaptation of Azospirillum to the rice rhizosphere microhabitat could involve the use of phenolic redox couples to refine the tuning of the bacterial environment to a redox value optimal for the functioning of nitrogenase, while keeping the advantage of using the respiratory electron transport chain to meet the high ATP requirement of nitrogen fixation.

Acknowledgments. This study was supported by a fellowship to A. B. awarded by the Centre National de la Recherche Scientifique, Paris (France). The authors thank Dr. R. Lensi for $\mathrm{N}_{2} \mathrm{O}$ suggestions and facilities, and Dr. R. Bally for Azospirillum strains and helpful scientific assistance.

\section{References}

1. Atlas RM, Bartha R (1981) Microbial ecology: fundamentals and applications. Addison-Wesley Pub., Reading, Mass.

2. Bally R, Thomas-Bauzon D, Heulin T, Balandreau J, Richard C, De Ley J (1983) Determination of the most frequent $\mathrm{N}_{2}$-fixing bacteria in a rice rhizosphere. Can J Microbiol 29:881-887

3. Barkovskii AL (1993) Biodestructive potential of symbiotic and of associative microorganisms to aromatic and haloaromatic compounds. In: Edyvean RG (ed) Effluent treatment and waste minimisation. (Chem Symp. ser., 132) Chameleon Press, London, pp 157-169

4. Barkovskii AL, Shub GM (1986) An Acinetobacter calcoaceticus strain utilizing various aromatic compounds and carrying a plasmid for resorcinol degradation. Mikrobiologija 55:237-240

5. Bassam BJ, Djordjevic MA, Redmond JW, Batley M, Rolfe BG (1988) Identification of a nodD-dependent locus in the Rhizobium strain NG234 activated by phenolic factor secreted by soybeans and other legumes. Mol Plant-Microbe Interact 1:161-168

6. Blum U, Wentworth TR, Klein K, Worsham AD, King LD, Geric TM, Lyu SW (1991) Phenolic acid content of soil from wheat no-till, wheat conventional-till, and fallow conventional-till soybean cropping system. J Chem Ecol 17:1045-1068

7. Burns RC, Hardy RWF (1975) Nitrogen fixation in bacteria and higher plants. Springer-Verlag, Berlin

8. Crane FL, Barr R (1985) Chemical structure and properties of coenzyme Q and related compounds. In: Lenaz $\mathrm{G}$ (ed) Coenzyme Q. Biochemistry, bioenergetics, and clinical applications of ubiquinone. Wiley \& Sons, New York, pp 1-39

9. Dagley S (1967) The microbial metabolism of phenolics. In: McLaren AD, Peterson GH (eds) Soil biochemistry. Marcel Dekker, Inc., New York, pp 287-317

10. Deiana S, Gessa C, Manunza B, Marchetti M, Usai M (1992) Mechanism and stoichiometry of the redox reaction between iron (III) and caffeic acid. Plant Soil 145:287-294

11. Einarsdottir GH, Stankovich MT, Tu S-C (1988) Studies of electron-transfer properties of salicylate hydroxylase from Pseudomonas cepacia and effects of salicylate and benzoate binding. Biochemistry 27:3277-3285

12. Flaig W, Beutelspacher H, Rietz E (1975) Chemical composition and physical properties of humic substances. In: Gieseking JE (ed) Soil components; v.1. Organic components. Springer-Verlag, Berlin, pp 1-211 
13. Flessa A, Fischer WR (1992) Plant-induced changes in the redox potential of rice rhizospheres. Plant Soil 143:55-60

14. Gajendiran N, Mahadevan A (1990) Plasmid-born catechol dissimilation in Rhizobium sp. FEMS Microbiol Ecol 73:125-130

15. Gasser F, Biville F, Turline G (1991) Un nouveau cofacteur d'oxydoreduction, la pyrroloquinoline quinone. Ann Inst Pasteur/Actualités 2:139-149

16. Givaudan A, Effosse A, Bally R (1991) Melanin production by Azospirillum lipoferum strains. In: Polsinelli M, Materassi R, Vincenzini M (eds) Nitogen fixation. (Developments in plant and soil sciences) Kluwer Academic, Dordrecht, pp 311-312

17. Givaudan A, Effosse A, Faure D, Potier P, Bouillant ML, Bally R (1993) Polyphenol oxidase in Azospirillum lipoferum isolated from rice rhizosphere: evidence of a laccase activity in non-motile strains of Azospirillum lipoferum. FEMS Microbiol Let 108:205-210

18. Haider K, Martin JP (1975) Decomposition of specifically carbon-14 labelled benzoic acid and cinnamic acid derivatives in soil. Soil Sci Soc Am Proc 39:657-662

19. Hardwood CS, Rivelli M, Orston LN (1984) Aromatic acids are chemoattractants for Pseudomonas putida. J Bacteriol 169:622-628

20. Harris RF (1982) Energetics of nitrogen transformations. In: Stevenson FJ (ed) Nitrogen in agricultural soils. (Agronomy series 22) ASA, CSA, and SSSA Pub, Madison, Wisconsin, pp $833-890$

21. Hartley RD, Whitehead DC (1985) Phenolic acids in soils and their influence on plant growth and soil microbial processes. In: Vaughan D, Malcolm RE (eds) Soil organic matter and biological activity. Martinus Nijhoff/DR W. Junk, Dordrecht, Germany, pp 109-149

22. Hartmann A, Fusseder A, Klingmüller W (1983) Mutants of Azospirillum affected in nitrogen fixation and auxin production. In: Klingmüller W (ed) Azospirillum. II. Genetics, physiology, ecology. (Experientia Suppl. 48) Birhäuser Verlag, Basel, pp 78-88

23. Havelka UD, Boyle MG, Hardy RWF (1982) Biological nitrogen fixation. In: Stevenson FJ (ed) Nitrogen in agricultural soils. (Agronomy series 22) ASA, CSA, and SSSA Pub, Madison, Wisconsin, pp 365-422

24. Heulin T, Weinhard P, Balandreau $\mathbf{J}$ (1983) Motility changes in Azospirillum lipoferum. In: Klingmüller W (ed) Azospirillum. II. Genetics, physiology, ecology. (Experientia Suppl 48) Birkhäuser Verlag, Basel, pp 89-94

25. Kape R, Parniske M, Werner D (1991) Chemotaxis and nod gene activity of Bradyrhizobium japonicum in response to hydroxycinnamic acids and isoflavonoids. Appl Environ Microbiol 57:316-319

26. Karasevitch $\mathrm{Yu} \mathrm{N}$ (1982) The foundation of selection for microorganisms utilizing synthetic organic compounds. Mir, Moscow

27. Korzhenevitch VI, Ignatov OV, Mironov AD, Krivopalov VV, Barkovskii AL (1991) Activity of bacterial strains destructors of aromatic compounds entrapped in agar gel beads. Prikladnaja Biokhim Mikrobiol 27:365-369

28. Krotzky A, Berggold R, Jaeger D, Dart PJ, Werner D (1983) Enhancement of aerobic nitrogenase activity (acetylene reduction assay) by phenol in soils and the rhizosphere of cereals. Z Pflanzenernaeher Bodenkd 146:634-642

29. Kuiters AT, Dennemann CAJ (1987) Water soluble phenolic substances in soils under several coniferous and deciduous tree species. Soil Biol Biochem 19:765-769

30. Kumada K (1987) Chemistry of soil organic matter. Elsevier, Amsterdam

31. Lehmann RG, Cheng HH (1988) Reactivity of phenolic acids in soil and formation of oxidation products. Soil Sci Soc Am J 52:1304-1309

32. Lehmann RG, Cheng HH, Harsh JB (1987) Oxidation of phenolic acids by soil iron and manganese oxides. Soil Sci Soc Am J 51:352-356

33. Le Strange KK, Bender GL, Djordjevic MA, Rolfe BG, Redmond JW (1990) The Rhizobium strain NGR234 nodD1 gene product responds to activation by the simple phenolic compounds vanillin and isovanillin present in wheat seedling extracts. Mol Plant-Microbe Interact 3-4:214-220

34. Lynch JM, Whipps JM (1990) Substrate flow in the rhizosphere. Plant Soil 129:1-10

35. Lynn DG, Chang M (1990) Phenolic signals in cohabitation: implications for plant development. Annu Rev Plant Physiol Plant Mol Biol 41:497-526 
36. Pflug W, Ziechmann W (1981) Inhibition of malate dehydrogenase by humic acids. Soil Biol Biochem 13:239-299

37. Schnitzer M (1978) Humic substances: chemistry and reactions. In: Schnitzer M, Khan SU (eds) Soil organic matter. Elsevier, Amsterdam, pp 1-64

38. Spaling GP, Ord BG, Vaughan D (1981) Changes in microbial biomass and activity in soils amended with phenolic compounds. Soil Biol Biochem 13:455-460

39. Swallow AJ (1982) Physical chemistry of semiquinones. In: Trumpower BL (ed) Function of quinones in energy conserving systems. Academic Press, London, pp 59-73

40. Thomas-Bauzon D, Weinhard P, Villecourt P, Balandreau J (1982) The spermosphere model. 1. Its use in growing, counting, and isolating nitrogen-fixing bacteria from the rizosphere of rice. Can J Microbiol 28:922-928

41. Ueckert J, Hurek T, Fendrik I, Niemann EG (1990) Radial gas diffusion from roots of rice (Oryza sativa $\mathrm{L}$.) and Kallar grass (Leptochloa fuska $\mathrm{L}$. Kunth.), and effect of inoculation with Azospirillum brasiliense Cd. Plant Soil 122:59-65

42. Vançura V, Kunc F (1988) Soil microbial associations: control of structures and functions. Elsevier, Amsterdam

43. von Zeichmann W (1972) Über die elektronen-Donator-und-Acceptor-Eingenschaften von Huminstoffen. Geoderma 8:111-131

44. von Ziechmann W (1977) MolekülKomplexe bei Huminstoffen durch e-Donator- und e-AcceptorStrukturen. Z Pflanzenernaehr Bodenkd 140:133-150

45. Werner D, Krotzky A, Berggold R, Thierfelder H, Preiss M (1982) Enhancement of specific nitrogenase activity in Azospirillum brasilense and Klebsiella pneumoniae, inhibition in Rhizobium japonicum under air by phenol. Arch Microbiol 132:51-56

46. Whitehead DC, Dibb H, Hartley RD (1983) Bound phenolic compounds in water extracts of soils, plant roots, and leaf litter. Soil Biol Biochem 15:133-136

47. Yoshinari T, Hynes R, Knowles R (1977) Acetylene inhibition of nitrous oxide reduction and measurement of denitrification and nitrogen fixation in soil. Soil Biol Biochem 9:177-183 